\title{
In vitro Evaluation of Fungal Endophytes against Major Fungal Pathogens of Groundnut
}

\author{
Sunilkumar Shirasangi* and Yashoda Hegde \\ Department of Plant Pathology, University of Agricultural Sciences, Dharwad- 580 005, \\ Karnataka, India \\ *Corresponding author
}

\section{A B S T R A C T}

\begin{tabular}{|c|}
\hline Keywords \\
\hline $\begin{array}{l}\text { Fungal endophytes, } \\
\text { Groundnut, In vitro, } \\
\text { Puccinia arachidis, } \\
\text { Rhizoctonia solani and } \\
\text { Sclerotium rolfsii }\end{array}$ \\
\hline Article Info \\
\hline $\begin{array}{l}\text { Accepted: } \\
06 \text { September } 2018 \\
\text { Available Online: } \\
10 \text { October } 2018\end{array}$ \\
\hline
\end{tabular}

Twenty eight fungal endophytes were isolated from leaves, 33 from stem and 21 from root, resulting in a total of 82 fungal endophytes from apparently healthy groundnut plant parts and evaluated these endophytes against major fungal pathogens viz., Sclerotium rolfsii and Rhizoctonia solani by dual culture technique and against Puccinia arachidis by spore germination technique. Among the leaf endophytes, LFDwAC-7 has shown maximum inhibition of mycelial inhibition of S. rolfsii $(46.30 \%)$, R. solani $(48.63 \%)$ and uredospore germination of $P$. arachidis $(52.88 \%)$. Among the stem endophytes, SFBeBu-18 and SFDwAC-8 have inhibited the maximum mycelial growth of $S$. rolfsii $(62.59 \%)$ and $R$. solani $(49.63 \%)$ respectively. Against $P$. arachidis SFBeBu-18 (56.91\%) has shown maximum inhibition of and uredospore germination. Among the root endophytes RFDwSo-34 has inhibited the maximum mycelial growth of $S$. rolfsii (43.70\%), RFDwSo-33 recorded the maximum mycelial inhibition and uredospore germination of $R$. solani $(49.80 \%)$ and $P$. arachidis $(47.84 \%)$.

\section{Introduction}

Groundnut (Arachis hypogaea L.) an annual herbaceous plant is considered to be one of the most important oilseed crops in the world. In India, the average yield of rabi/summer groundnut is around $1600 \mathrm{~kg} / \mathrm{ha}$, whereas kharif groundnut is around $1000 \mathrm{~kg} / \mathrm{ha}$ which is lower than major groundnut growing countries. This may be attributed to the rainfed nature of cultivation of this crop coupled with attack by a variety of biotic and abiotic stresses and more than 55 pathogens have been reported to affect groundnut (Subrahmaniyam et al., 1985). Among the diseases, stem rot, collar rot, root rot, leaf spots (early and late) and rust have been recognized as economically important diseases.

To manage such diseases, farmers presently use different fungicides with spray schedules utilizing two or more different fungicide groups or fungicide formulations containing two different chemical groups, which have resulted in several undesirable effects like pesticide pollution, fungicide resistance, elimination of beneficial fauna, environmental pollution and human health hazards (Ghewande, 2008). So integrated disease 
management where biological control as one practice is becoming a key consideration for disease management. Use of endophytes as biocontrol agent may open up new area of research in plant protection in the recent decades under various agro-climatic situations. The term "endophyte" is derived from the Greek word "endon" means within and "phyte" means plant so the term includes all organisms that, during a variable period of their life, symptomlessly colonize the living internal tissues of their hosts (Stone et al., 2000). Fungal endophytes live in intercellular space or inside cells of host plant causing no apparent damage (Saikkonen et al., 1998). Fungi belonging to this group are ubiquitous and plant species not associated to fungal endophytes are not known. However, endophytic fungi, which colonize and grow asymptomatically within healthy plant tissues may evolve from plant pathogenic fungi and become non-pathogenic. They are found in almost all kinds of plants, including trees, grass, algae and herbaceous plants. They will produce plant-growth-regulatory, antimicrobial, antiviral or insecticidal substances to enhance the growth and competitiveness of the host in nature (Carroll, 1988). With this background, in the present study an attempt was made to isolate fungal endophytes and evaluate them under in vitro condition against soilborne and airborne fungal pathogens.

\section{Materials and Methods}

\section{Isolation of fungal endophytes}

A roving survey was conducted during 2016 and 2017 to isolate fungal endophytes in groundnut. Apparently healthy leaves, stems and root samples were collected from the fields of Bagalkot, Belagavi, Dharwad and Haveri districts of northern Karnataka. Collected plant samples were washed in running tap water to remove soil dirt and debris and cut into $1 \mathrm{~cm}$ sections. After this, surface sterilization was done with 70 per cent ethanol for a minute followed by 1 per cent sodium hypochlorite for 3 minutes. Subsequently the sections were rinsed with sterile distilled water and placed on $9 \mathrm{~cm}$ Petri plates containing potato dextrose agar (PDA) medium amended with streptomycin (250 $\mathrm{mg} / \mathrm{l})$ to slow down the bacterial growth. Sterilized tissue segments were pressed onto the surface of PDA medium to check the efficacy of surface sterilization procedure and to confirm endophytic isolations only from internal tissues of the plant segments. The absence of growth of any fungi on the medium confirmed that the surface sterilization procedure was effective in removing the surface fungi (Schulz et al., 1993). All plates were incubated at $25 \pm 1^{\circ} \mathrm{C}$ and observed for fungal growth at daily interval up to 7-10 days. Fungi growing out from the plant tissues were transferred on to fresh PDA medium. After purifying the isolates for several times, final pure cultures were transferred on to PDA slants and stored in refrigerator at $4{ }^{\circ} \mathrm{C}$ for further studies.

\section{In vitro evaluation of fungal endophytes against $S$. rolfsii and $R$. solani by dual culture method}

Dual culture technique was adopted for antagonistic activity of isolated endophytes against $S$. rolfsii, $R$. solani and $F$. solani on PDA plates (Deepa and Sally, 2015). In dual culture technique $20 \mathrm{ml}$ of sterilized and cooled PDA was poured into sterilized Petri plates. Fungal endophytes were evaluated by inoculating the pathogen at one side of Petri plate and the fungal endophyte inoculated at exactly opposite side of the same plate by leaving 3-4 cm gap. For this, actively growing cultures were used with three replications. After required period of incubation i.e., after growth of colony in control plate reached 90 $\mathrm{mm}$ diameter, the radial growth of pathogen in treated plate was measured. Per cent inhibition 
over control was worked out according to formula given by Vincent (1947).

$\mathrm{I}=\frac{\mathrm{C}-\mathrm{T}}{\mathrm{C}}$

Where, $\mathrm{I}=$ Per cent inhibition of mycelial growth, $\mathrm{C}=$ Radial growth in control $(\mathrm{mm})$ and $\mathrm{T}=$ Radial growth in treatment $(\mathrm{mm})$.

\section{In vitro evaluation of fungal endophytes against $P$. arachidis by spore germination method}

25 per cent concentrated culture filtrate of each endophytic isolate was prepared and it was used for uredospore germination study in cavity slides. In a cavity slide, $25 \mu$ of above mentioned concentration of culture filtrate was separately taken and around hundred uredospores were added per cavity by scrapping rust pustule. The cavity slides were kept in the moist chamber and were incubated at $20^{\circ} \mathrm{C}$. Three replications were maintained for each treatment. Uredospore germination was observed at $24 \mathrm{hrs}$ after incubation at 100X magnification. Later per cent inhibition over control was calculated by using formula given by Vincent (1947).

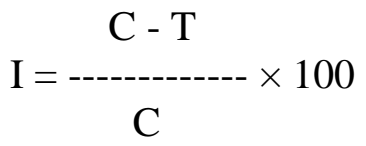

Where, $\mathrm{I}=$ Per cent inhibition of spore germination, $\mathrm{C}=$ Number of spores germinated in control and $\mathrm{T}=$ Number of spores germinated in treatment.

\section{Results and Discussion}

A total of 82 (28 from leaf, 33 from stem and 21 from root) fungal endophytes were isolated from apparently healthy groundnut plant parts and evaluated these endophytes against major fungal pathogens viz., S. rolfsii, $R$. solani by dual culture technique and against $P$. arachidis by spore germination technique.

Among 28 leaf endophytes, the maximum mycelial inhibition against $S$. rolfsii was observed by the leaf endophyte LFDwAC-7 $(46.30 \%)$ which was significantly superior to other endophytes. This was followed by LFDwAC-6 (36.30 \%), LFBaBa-26 (34.81\%) and LFBaCh-28 (34.81\%) which were on par with each other. The isolates LFBeBu-15 (1.11\%), LFBePa-14 (1.85\%) and LFDwHe$22(1.85 \%)$ were ineffective with least mycelial inhibition. Against $R$. solani, the endophyte LFDwAC-7 (48.63\%) showed the maximum mycelial inhibition which was on par with LFDwAC-9 (46.67 \%), LFBaBa-26 $(46.67 \%)$ and LFBeAV-21 (45.88 \%). The endophyte LFDwAC-4 (3.14 \%) showed the least mycelial inhibition. Against $P$. arachidis, the isolate LFDwAC-7 (52.88 \%), LFBaBa-26 $(52.67 \%)$ and LFBeAV-21 (51.95\%) showed maximum inhibition of uredospore germination. The isolate LFBaCh-27 (13.10 $\%)$ and LFDwBi-25 (16.57 \%) were less effective with minimum inhibition of uredospore germination as compared to other endophytes and the results are depicted in Table 1 and Plate 1.

Among 33 stem endophytes, the maximum mycelial inhibition of $S$. rolfsii was observed in the stem endophyte SFBeBu-18 (62.59\%) which was on par with SFDwAC-11 (54.44 $\%)$ and SFBePa-17 (51.48 \%). The endophyte SFDwAC-10 was less effective with least mycelial inhibition (29.26\%). Against $R$. solani, the endophyte SFDwAC-8 showed the maximum mycelial inhibition of 49.63 per cent which was on par with SFDwAC-7 $(48.15 \%)$ and SFDwBi-33 (47.78\%). The endophyte SFDwAC-15 was less effective with the least mycelial inhibition (22.22 \%) followed by SFBeKh-24 (25.56 \%). 
Table.1 In vitro evaluation of groundnut leaf fungal endophytes against Sclerotium rolfsii, Rhizoctonia solani and Puccinia arachidis

\begin{tabular}{|c|c|c|c|}
\hline \multirow[t]{3}{*}{ Endophyte } & \multicolumn{3}{|c|}{ Per cent inhibition of } \\
\hline & \multicolumn{2}{|c|}{ Mycelial growth } & \multirow{2}{*}{$\begin{array}{c}\text { Spore germination } \\
P \text {. arachidis }\end{array}$} \\
\hline & S. rolfsii & R. solani & \\
\hline LFDwAC-1 & $8.52(16.96)^{*}$ & $39.61(38.98)^{*}$ & $34.82(36.15)^{*}$ \\
\hline LFDwAC-2 & $5.93(14.07)$ & $37.65(37.80)$ & $42.31(40.56)$ \\
\hline LFDwAC-3 & $5.56(13.63)$ & $14.51(22.31)$ & $38.83(38.53)$ \\
\hline LFDwAC-4 & $11.48(19.79)$ & $3.14(10.16)$ & $44.54(41.85)$ \\
\hline LFDwAC-5 & $29.26(32.73)$ & $33.73(35.46)$ & $25.98(30.62)$ \\
\hline LFDwAC-6 & $36.30(37.03)$ & $41.57(40.13)$ & $25.53(30.33)$ \\
\hline LFDwAC-7 & $46.30(42.86)$ & $48.63(44.19)$ & $52.88(46.63)$ \\
\hline LFDwAC-8 & $21.85(27.86)$ & $40.00(39.19)$ & $37.33(37.65)$ \\
\hline LFDwAC-9 & $2.59(9.22)$ & $46.67(43.07)$ & $29.72(33.02)$ \\
\hline LFDwAC-10 & $18.52(25.48)$ & $41.57(40.13)$ & $36.15(36.94)$ \\
\hline LFDwAC-11 & $2.59(9.22)$ & $15.69(23.30)$ & $33.42(35.30)$ \\
\hline LFBePa-12 & $14.81(22.63)$ & $36.86(37.36)$ & $42.72(40.79)$ \\
\hline LFBePa-13 & $28.15(32.03)$ & $41.96(40.35)$ & $36.66(37.24)$ \\
\hline LFBePa-14 & $1.85(7.73)$ & $38.82(38.53)$ & $28.29(32.11)$ \\
\hline LFBeBu-15 & $1.11(6.05)$ & $30.59(33.54)$ & $31.70(34.25)$ \\
\hline LFBeBu-16 & $27.04(31.32)$ & $40.78(39.66)$ & $29.21(32.70)$ \\
\hline LFBeSi-17 & $2.59(9.22)$ & $40.78(39.67)$ & $16.99(24.32)$ \\
\hline LFBeKh-18 & 3.70 (11.07) & $38.43(38.29)$ & $29.66(32.98)$ \\
\hline LFBeJa-19 & $4.07(11.62)$ & $40.78(39.67)$ & $28.44(32.20)$ \\
\hline LFBeAv-20 & $2.96(9.87)$ & $41.96(40.36)$ & $28.40(32.19)$ \\
\hline LFBeA V-21 & $2.96(9.87)$ & $45.88(42.62)$ & $51.95(46.10)$ \\
\hline LFDwHe-22 & $1.85(7.73)$ & $40.39(39.44)$ & $32.51(34.74)$ \\
\hline LFDwSo-23 & $5.93(14.07)$ & $39.61(38.99)$ & $22.22(28.08)$ \\
\hline LFDwSo-24 & $2.59(9.22)$ & $38.43(38.30)$ & $20.10(26.62)$ \\
\hline LFDwBi-25 & $2.22(8.57)$ & $39.61(38.98)$ & $16.57(24.01)$ \\
\hline LFBaBa-26 & $34.81(36.14)$ & $46.67(43.07)$ & $52.67(46.51)$ \\
\hline LFBaCh-27 & $12.96(21.09)$ & $33.73(35.48)$ & $13.10(21.20)$ \\
\hline LFBaCh-28 & $34.81(36.14)$ & $34.12(35.72)$ & $24.82(29.85)$ \\
\hline S.Em. \pm & 0.46 & 0.96 & 0.62 \\
\hline C.D. (1\%) & 1.73 & 3.61 & 2.33 \\
\hline C.V. & 4.17 & 4.49 & 3.11 \\
\hline
\end{tabular}

*Arc sine values 
Table.2 In vitro evaluation of groundnut stem fungal endophytes against Sclerotium rolfsii, Rhizoctonia solani and Puccinia arachidis

\begin{tabular}{|c|c|c|c|}
\hline \multirow[t]{3}{*}{ Endophyte } & \multicolumn{3}{|c|}{ Per cent inhibition of } \\
\hline & \multicolumn{2}{|c|}{ Mycelial growth } & \multirow{2}{*}{$\begin{array}{c}\text { Spore germination } \\
\text { P. arachidis }\end{array}$} \\
\hline & S. rolfsii & R. solani & \\
\hline SFDwAC-2 & $39.26(38.70)^{*}$ & $43.33(41.15)$ & $28.74(32.40)^{*}$ \\
\hline SFDwAC-3 & $33.33(35.24)$ & $41.48(40.07)$ & $3.94(10.48)$ \\
\hline SFDwAC-4 & $48.15(43.88)$ & $35.93(36.81)$ & $36.32(37.04)$ \\
\hline SFDwAC-5 & $39.63(38.97)$ & $41.48(40.08)$ & $30.42(33.45)$ \\
\hline SFDwAC-7 & $31.85(34.34)$ & $48.15(43.92)$ & $49.40(44.64)$ \\
\hline SFDwAC-8 & $41.11(39.81)$ & $49.63(44.77)$ & $47.15(43.34)$ \\
\hline SFDwAC-9 & $37.04(37.46)$ & $37.41(37.69)$ & $28.61(32.31)$ \\
\hline SFDwAC-10 & $29.26(32.73)$ & $37.04(37.47)$ & $25.81(30.52)$ \\
\hline SFDwAC-11 & $54.44(47.55)$ & $37.41(37.69)$ & $55.18(47.96)$ \\
\hline SFDwAC-12 & $39.63(38.91)$ & $38.15(38.13)$ & $35.36(36.47)$ \\
\hline SFDwAC-13 & $41.48(40.06)$ & $39.63(39.00)$ & $40.37(39.43)$ \\
\hline SFDwAC-14 & $36.67(37.25)$ & $32.22(34.57)$ & $14.89(22.64)$ \\
\hline SFDwAC-15 & $41.48(40.04)$ & $22.22(28.11)$ & $35.53(36.56)$ \\
\hline SFBePa-16 & $43.70(41.31)$ & $35.93(36.81)$ & $31.88(34.36)$ \\
\hline SFBePa-17 & $51.48(45.83)$ & $38.89(38.55)$ & $48.65(44.21)$ \\
\hline SFBeBu-18 & $62.59(52.28)$ & $35.56(36.58)$ & $56.91(48.96)$ \\
\hline SFBeBu-19 & $45.19(42.18)$ & $38.52(38.35)$ & $33.03(35.04)$ \\
\hline SFBeSi-20 & $39.26(38.75)$ & $44.44(41.79)$ & $36.74(37.28)$ \\
\hline SFBeSi-21 & $33.70(35.47)$ & $33.33(35.25)$ & $33.69(35.46)$ \\
\hline SFBeKh-22 & $34.44(35.92)$ & $27.04(31.30)$ & $45.75(42.54)$ \\
\hline SFBeKh-23 & $37.04(37.47)$ & $37.04(37.47)$ & $26.64(31.05)$ \\
\hline SFBeKh-24 & $35.19(36.37)$ & $25.56(30.33)$ & $40.17(39.31)$ \\
\hline SFBeJa-25 & $41.11(39.86)$ & $36.30(37.03)$ & $13.67(21.62)$ \\
\hline SFBeA v-26 & $35.93(36.80)$ & $30.37(33.42)$ & $42.55(40.69)$ \\
\hline SFBeA v-27 & $33.70(35.47)$ & $27.04(31.30)$ & $20.15(26.66)$ \\
\hline SFBeA v-28 & $33.33(35.25)$ & $33.33(35.25)$ & $44.81(42.00)$ \\
\hline SFDwSo-29 & $40.37(39.42)$ & $39.63(39.00)$ & $33.12(35.12)$ \\
\hline SFDwSo-30 & $34.81(36.14)$ & $43.33(41.15)$ & $36.36(37.05)$ \\
\hline SFDwKa-31 & $35.93(36.81)$ & $28.15(32.01)$ & $30.18(33.30)$ \\
\hline SFDwBi-32 & $35.93(36.80)$ & $36.30(37.03)$ & $32.55(34.77)$ \\
\hline SFDwBi-33 & $37.78(37.89)$ & $47.78(43.71)$ & $51.84(46.04)$ \\
\hline SFDwUn-34 & $39.63(39.00)$ & $38.89(38.56)$ & 37.88 (37.97) \\
\hline SFBaCh-35 & $40.37(39.43)$ & $44.07(41.57)$ & $31.54(34.14)$ \\
\hline S.Em. \pm & 1.81 & 0.70 & 1.02 \\
\hline C.D. (1\%) & 6.78 & 2.62 & 3.83 \\
\hline C.V. & 8.05 & 3.22 & 4.93 \\
\hline
\end{tabular}

*Arc sine values 
Table.3 In vitro evaluation of groundnut root fungal endophytes against Sclerotium rolfsii, Rhizoctonia solani and Puccinia arachidis

\begin{tabular}{|c|c|c|c|}
\hline \multirow[t]{3}{*}{ Endophyte } & \multicolumn{3}{|c|}{ Per cent inhibition of } \\
\hline & \multicolumn{2}{|c|}{ Mycelial growth } & \multirow{2}{*}{$\begin{array}{c}\text { Spore germination } \\
\text { P. arachidis }\end{array}$} \\
\hline & S. rolfsii & R. solani & \\
\hline RFDwAC-7 & $32.96(35.02)^{*}$ & $44.71(41.94)$ & 6.35 (14.59) \\
\hline RFDwAC-8 & $34.44(35.92)$ & 48.24 (43.97) & $17.71(24.87)$ \\
\hline RFDwAC-9 & $30.37(33.41)$ & $46.27(42.84)$ & $20.17(26.68)$ \\
\hline RFDwAC-15 & $31.48(34.11)$ & $35.69(36.66)$ & $28.59(32.31)$ \\
\hline RFDwAC-16 & $35.93(36.80)$ & $42.75(40.81)$ & $32.90(34.98)$ \\
\hline RFDwAC-17 & $32.59(34.80)$ & $41.96(40.36)$ & $47.07(43.30)$ \\
\hline RFBePa-22 & $32.22(34.57)$ & $34.12(35.73)$ & $45.30(42.28)$ \\
\hline RFBeJa-29 & $38.52(38.35)$ & $41.57(40.13)$ & $38.08(38.09)$ \\
\hline RFBeJa-30 & $32.59(34.80)$ & $36.47(37.13)$ & $43.81(41.42)$ \\
\hline RFBeAv-31 & $30.74(33.66)$ & $25.49(30.30)$ & $29.51(32.89)$ \\
\hline RFBeAv-32 & $38.52(38.35)$ & $36.47(37.12)$ & $22.36(28.20)$ \\
\hline RFDwSo-33 & $40.74(39.64)$ & $49.80(44.87)$ & $47.84(43.74)$ \\
\hline RFDwSo-34 & $43.70(41.37)$ & $47.45(43.52)$ & $42.79(40.78)$ \\
\hline RFDwSo-35 & $40.74(39.65)$ & $39.61(38.99)$ & $25.82(30.50)$ \\
\hline RFDwUn-37 & $42.59(40.72)$ & $41.18(39.90)$ & $28.12(30.83)$ \\
\hline RFBaCh-38 & $36.30(37.03)$ & $42.35(40.58)$ & $22.65(28.41)$ \\
\hline RFBaCh-39 & $29.26(32.73)$ & $43.92(41.49)$ & $42.48(40.66)$ \\
\hline RFHaBn-40 & $34.81(36.14)$ & $43.53(41.27)$ & $32.57(34.71)$ \\
\hline RFHaBn-41 & $30.37(33.43)$ & $45.88(42.62)$ & $31.92(34.39)$ \\
\hline RFHaBd-42 & $31.48(34.12)$ & $41.96(40.35)$ & $15.93(23.50)$ \\
\hline RFHaBd-43 & $25.93(30.59)$ & $44.71(41.94)$ & $37.95(38.01)$ \\
\hline S.Em. \pm & 0.50 & 0.71 & 1.11 \\
\hline C.D. $(1 \%)$ & 1.92 & 2.72 & 4.23 \\
\hline C.V. & 2.43 & 3.08 & 5.72 \\
\hline
\end{tabular}

*Arc sine values 
Plate.1 In vitro evaluation of groundnut leaf fungal endophytes against $S$. rolfsii and $R$. solani by dual culture method

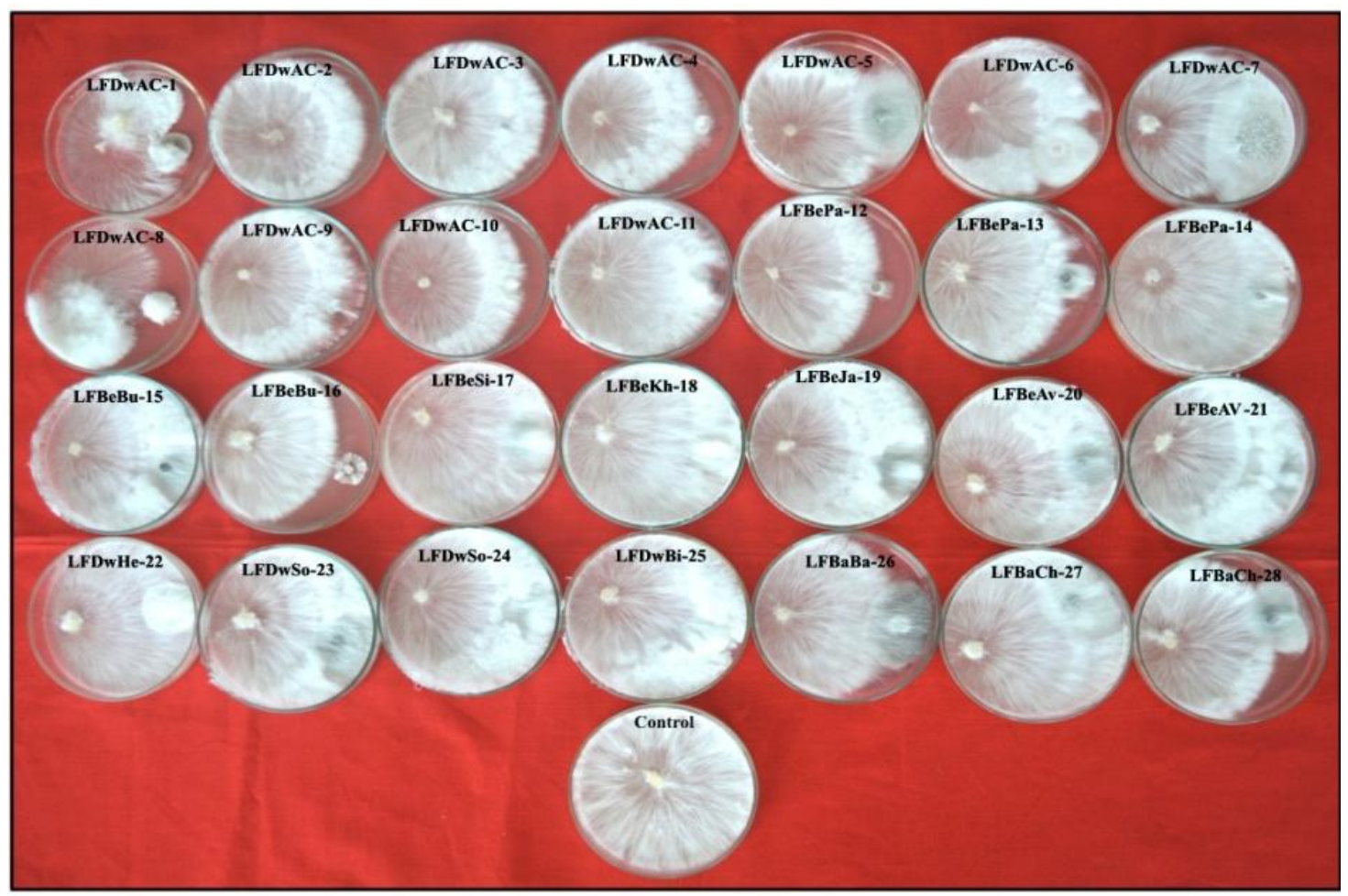

a) Sclerotium rolfsii

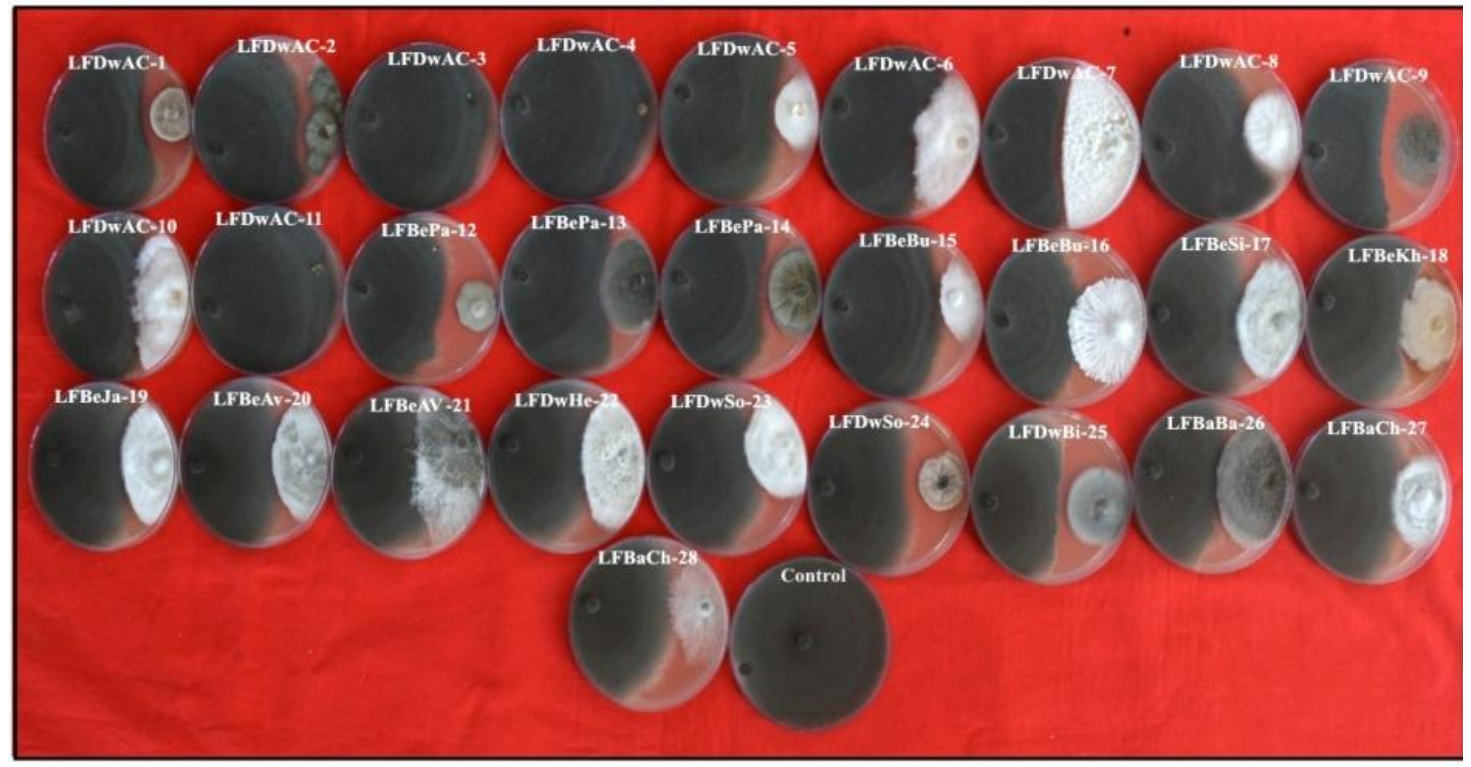

b) Rhizoctonia solani 
Plate.2 In vitro evaluation of groundnut stem fungal endophytes against $S$. rolfsii and $R$. solani by dual culture method

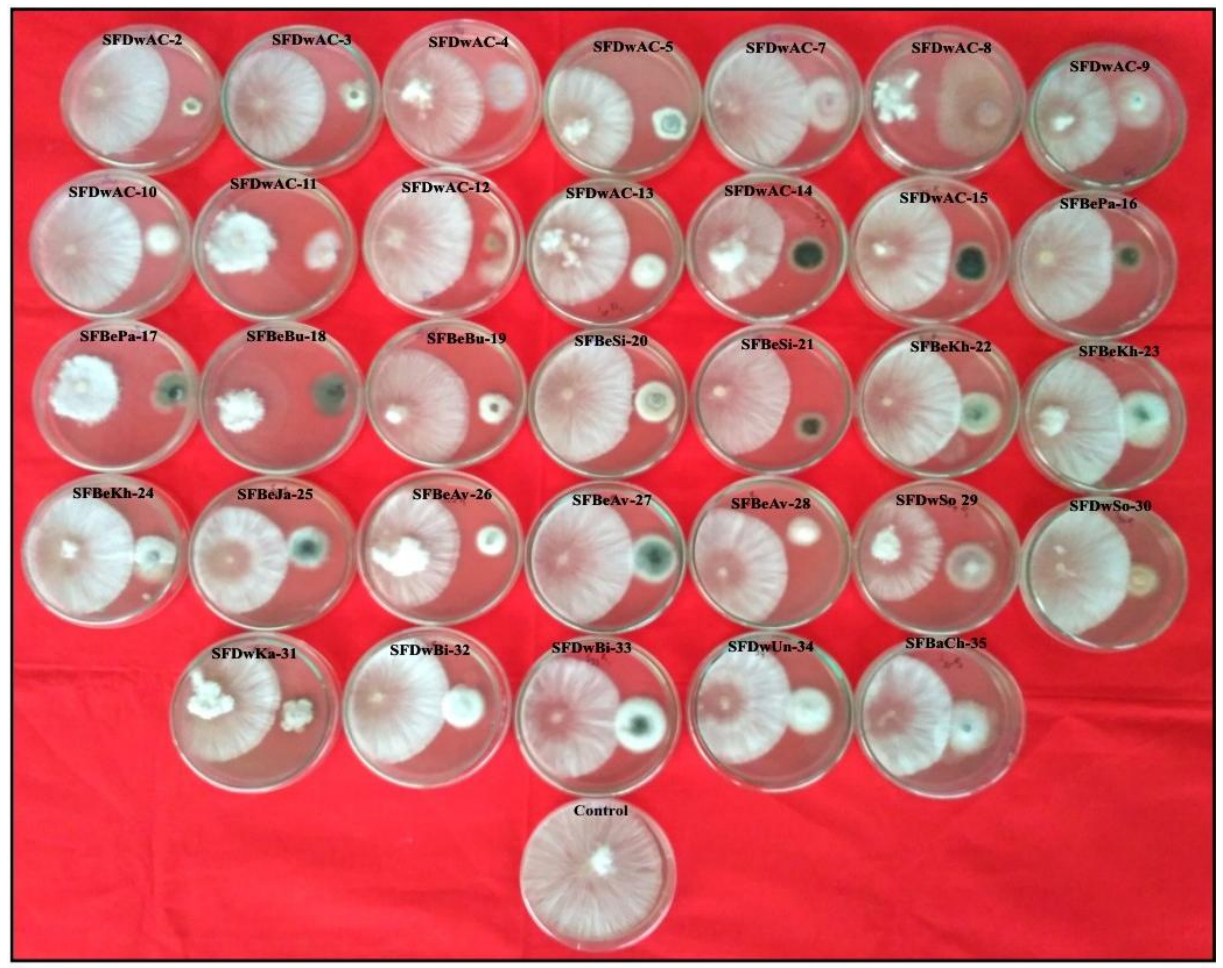

a) Sclerotium rolfsii

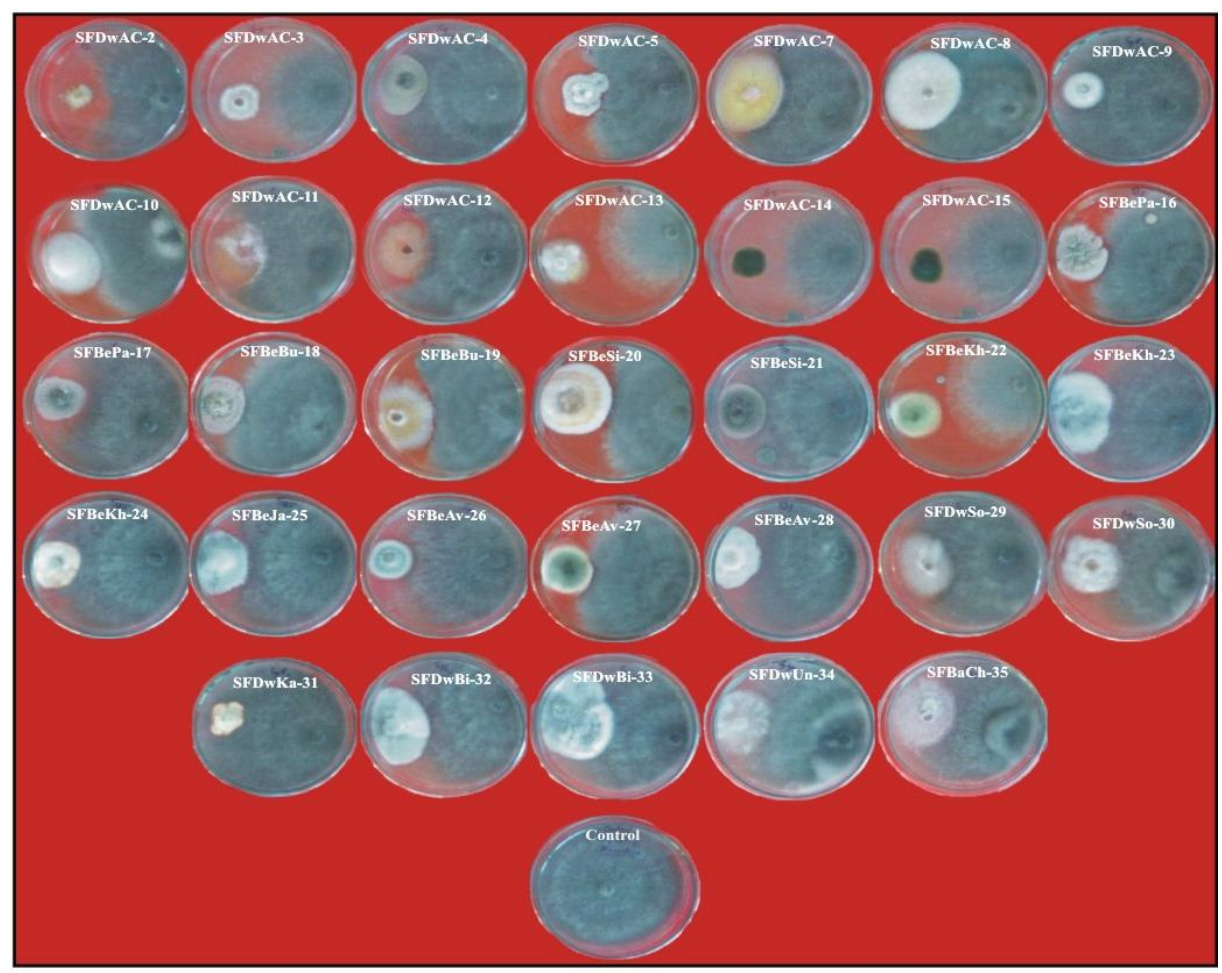

b) Rhizoctonia solani 
Plate.3 In vitro evaluation of groundnut root fungal endophytes against $S$. rolfsii and $R$. solani by dual culture method

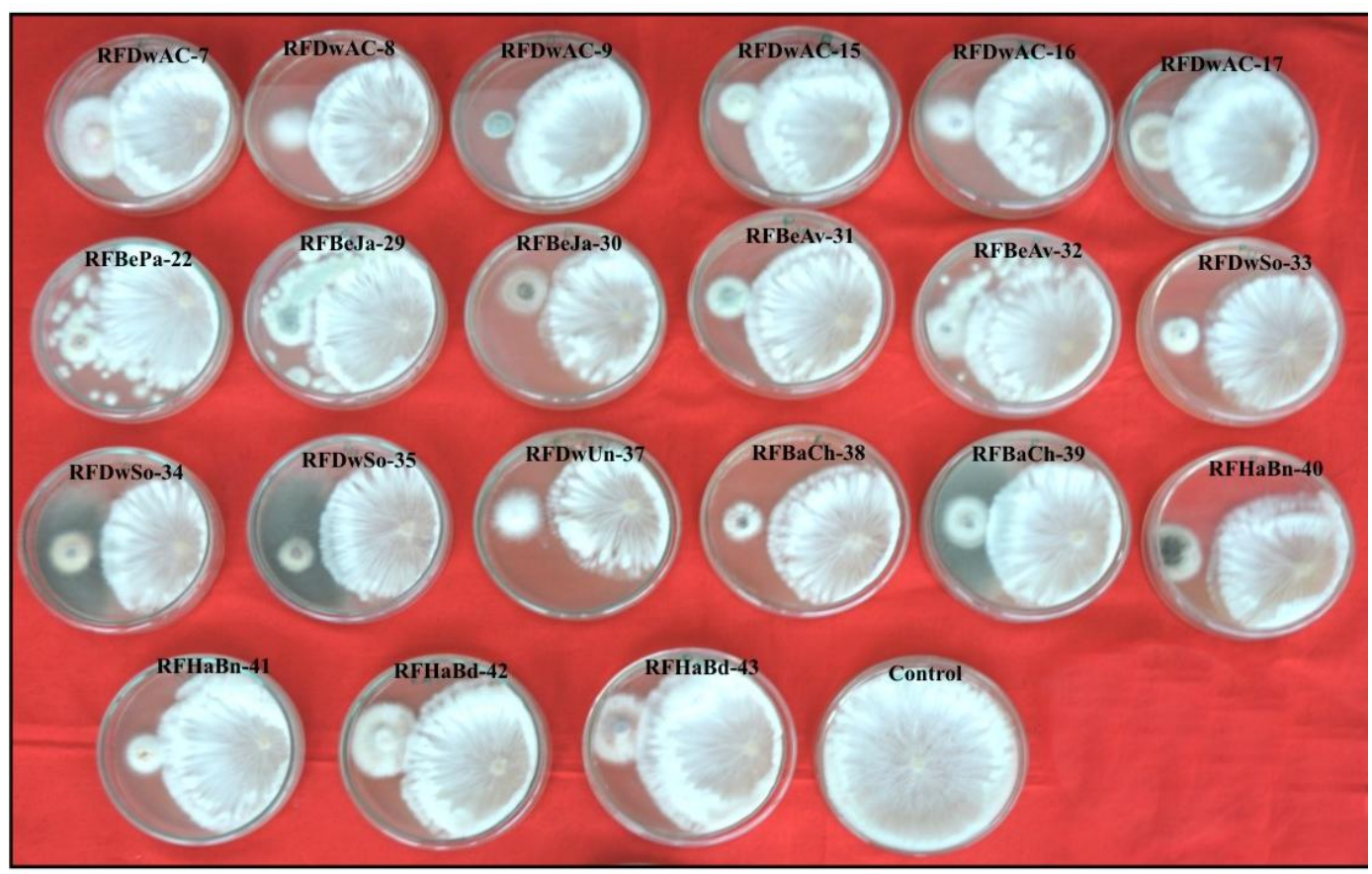

a) Sclerotium rolfsii

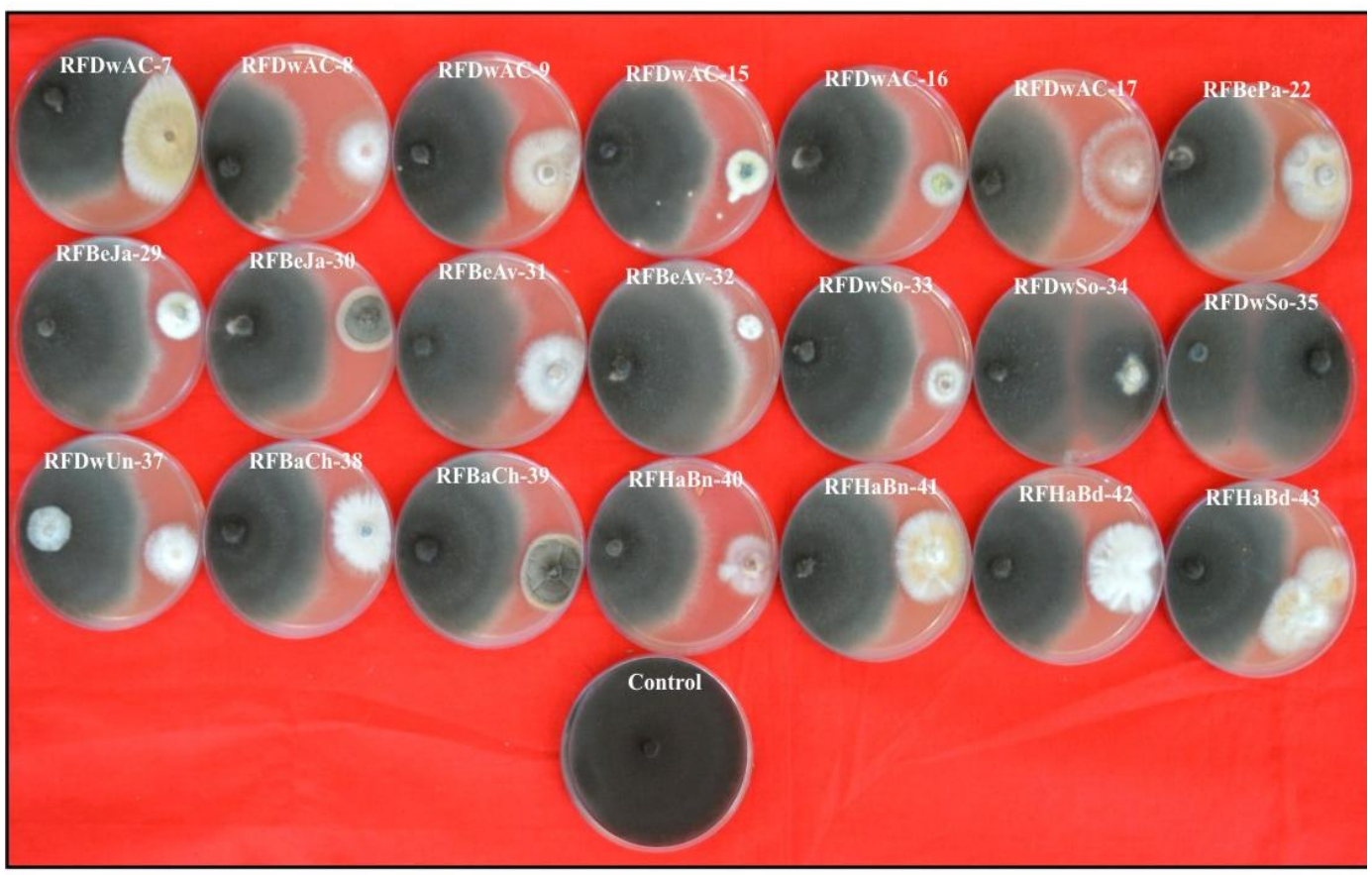

b) Rhizoctonia solani 
Plate.4 In vitro evaluation of groundnut fungal endophytes against $P$. arachidis by spore germination technique

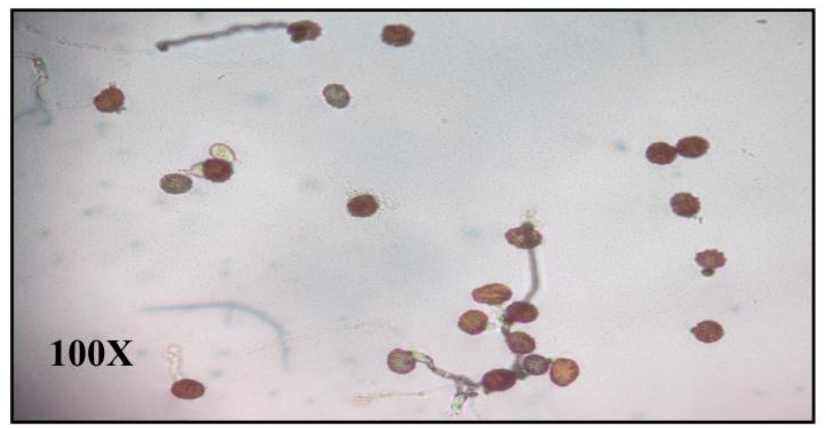

a) LFDwAC-7

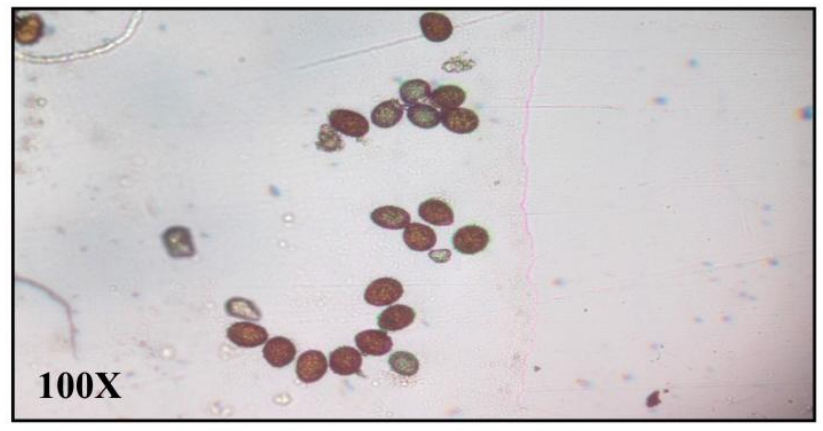

b) SFBeBu-18

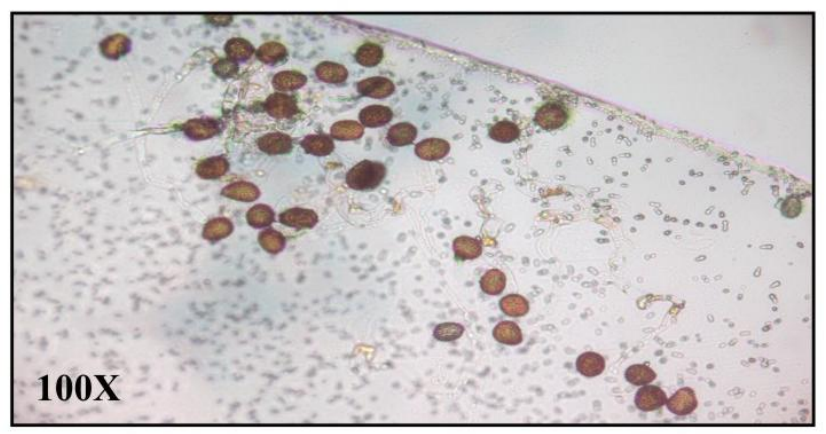

c) RFDwSo-34

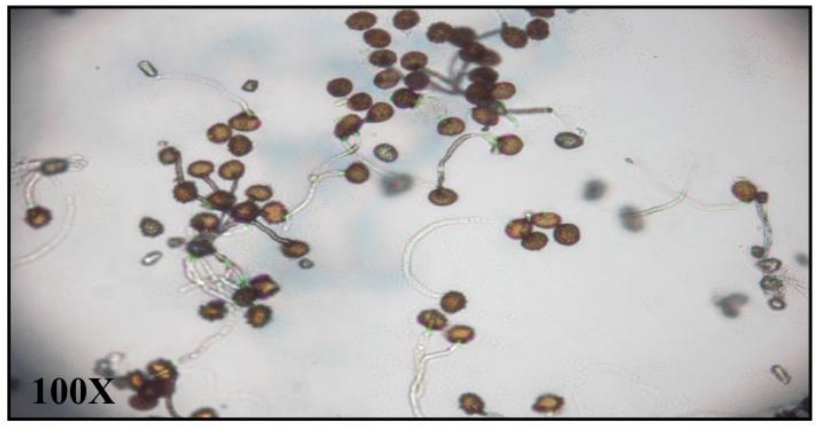

d) Control 
Against $P$. arachidis, the endophyte $\mathrm{SFBeBu}-$ $18(56.91 \%)$ recorded the maximum inhibition of uredospore germination which was on par with SFDwAC-11 (55.18\%). The endophyte SFDwAC-3 (3.94 \%) recorded the least inhibition of uredospore germination as compared to other endophytes (Table 2 and Plate 2).

Among 21 root endophytes, the maximum mycelial inhibition against $S$. rolfsii was observed by the root endophyte RFDwSo-34 (43.70\%) which was on par with RFDwUn37 (42.59 \%), RFDwSo-33 (40.74\%) and RFDwSo-35 (40.74 \%). The endophyte RFHaBd-43 (25.93\%) was less effective with the least mycelial inhibition. Against $R$. solani, the endophyte RFDwSo-33 (49.80\%) showed the maximum mycelial inhibition which was on par with RFDwAC-8 (48.24 $\%)$, RFDwSo-34 (47.45 \%) and RFDwAC-9 (46.27\%). The endophyte RFBeAv-31 (25.49 $\%)$ showed the least mycelial inhibition and it was less effective as compared to other endophytes. Against $P$. arachidis, the endophyte RFDwSo-33 (47.84 \%) recorded the maximum inhibition of uredospore germination and this was on par with RFDwAC-17 (47.07 \%), RFBePa-22 (45.30 $\%)$ and RFBeJa-30 (43.81\%). The endophyte RFDwAC-7 (6.35\%) was recorded the least inhibition of uredospore germination as compared to other endophytes evaluated and the results are presented in Table 3 and Plate 3.

Endophytes could become better biocontrol agents as compared with rhizosphere micro flora because they do not compete for nutrition and/or niche in apoplast. Endophytic microorganisms may increase the plant fitness by improving the tolerance to heavy metals and drought could promote plant growth and reduce the herbivory or phytopathogen settling (Rubini et al., 2005). Results of present in vitro studies on efficacy of endophytes against three pathogens like $S$. rolfsii, $R$. solani and $P$. arachidis revealed that there is a significant inhibition of pathogens from fungal endophytes in dual culture.

In dual culture method among the 82 fungal endophytes, 10 endophytes (LFDwAC-7, LFBaBa-26, SFDwAC-7, SFDwAC-8, SFDwAC-11, SFBePa-17, SFBeBu-18, SFDwBi-33, RFDwSo-33 and RFDwSo-34) have shown maximum inhibition of mycelium/uredospore germination of all three pathogens. These endophytes were fast growing and were more effective against one and the other pathogens.

All these endophytes showed the clear inhibition zone and inhibition of uredospore germination, which may be due to the production of antimicrobial compounds from the endophytes.

The findings of the present study are in agreement with Durga Prasada (2008), Seema and Devaki (2012) and Ghewande (2008) who evaluated fungal endophytes against $S$. rolfsii, $R$. solani and $P$. arachidis respectively by employing dual culture method and spore germination test.

In dual culture method, the extent of inhibition of $S$. rolfsii and $R$. solani by fungal endophytes ranged from 1.11 to 62.59 per cent and 3.14 to 53.73 per cent, respectively. The inhibition of uredospore germination by fungal endophytes was ranged from 3.94 to 68.28 per cent. Among the fungal endophytes, SFBeBu-18 (62.59 \%) showed the maximum mycelial inhibition of $S$. rolfsii followed by TSFE-7 (54.12 \%) and TSFE-4 (53.73\%) showed the maximum mycelial inhibition of $R$. solani followed by TLFE-4 (53.33\%) and against $P$. arachidis TSFE-7 (68.28 \%) showed maximum inhibition of uredospore germination followed by TLFE-7 (65.97\%). 


\section{References}

Carroll, G., 1988, Fungal endophytes in stems and leaves: from latent pathogen to mutualistic symbiont. Ecolo., 69: 2-9.

Deepa, J. and Sally, K., 2015, Antagonistic activity of endophytic microorganisms against bacterial wilt disease of tomato. Inter. J. Current Advanced Res., 4(10): 399-404.

Durga Prasad, S., 2008, Genetic diversity and biological control of Sclerotium rolfsii (Sacc.) causing stem rot of groundnut (Arachis hypogaea L.). M. Sc. Thesis, Acharya N. G. Ranga Agril. Univ., Rajendra nagar, Hyderabad, India.

Ghewande, M. P., 2008, Biological control of groundnut (Arachis hypogaea L.) rust (Puccinia arachidis Speg.) in India. Tropical Pest Manag., 36 (1):17-20.

Rubini, M. R., Silva, R.T., Pomella, A. W. V., Maki, C. S., Araujo, W. L., Santos, D.R. and Azevedo, J. L., 2005. Diversity of endophytic fungal community of cacao (Theobroma cacao L.) and biological control of Crinipellis perniciosa, causal agent of witches' broom disease. Int. J. Biol. Sci., 1(1): 24-33.
Saikkonen, K., Faeth, S. H., Helander, M. and Sullivan, T. J., 1998, Fungal endophytes: a continuum of interactions with host plants. Annu. Rev. Ecol. Syst., 29: 319-343.

Schulz, B., Wanke, U. and Draeger, S., 1993, Endophytes from herbaceous and shrubs: effectiveness of surface sterilization methods. Mycol. Res., 97:1447-50.

Seema, M. and Devaki, N. S., 2012, In vitro evaluation of biological control agents against Rhizoctonia solani. J. Agric. Tech., 8(1): 233-240.

Stone, J. K., Bacon, C. W. and White, J. F., 2000, An overview of endophytic microbes: endophytism defined. Microbiol. Endophytes. Marcel Dekker, New York, pp. 3-30.

Subrahmaniyam, P., Reddy, L. J., Gibbons, R. W. and Donald, M. D., 1985, Peanut rust: a major threat to peanut production in the semi-arid tropics. Plant Dis. 69: 813-819.

Vincent, J. M., 1947, Distortion of fungal hyphae in the presence of certain inhibitors. Nature, 150: p 850.

\section{How to cite this article:}

Sunilkumar Shirasangi and Yashoda Hegde. 2018. In vitro Evaluation of Fungal Endophytes against Major Fungal Pathogens of Groundnut. Int.J.Curr.Microbiol.App.Sci. 7(10): 469-480. doi: https://doi.org/10.20546/ijcmas.2018.710.051 